\title{
Experimental Investigation on the Crack Evolution of Marine Shale with Different Soaking Fluids
}

\author{
Lei Wang ${ }^{1}$, Zhenhui Bi ${ }^{1,3 *}$, Yijin Zeng ${ }^{2}$, Guangguo Yang ${ }^{2}$, Yintong Guo ${ }^{1}$ and Hanzhi Yang ${ }^{3}$ \\ ${ }^{1}$ State Key Laboratory of Geomechanics and Geotechnical Engineering, Institute of Rock and Soil Mechanics, Chinese Academy \\ of Sciences, Wuhan, China, ${ }^{2}$ Sinopec Research Institute of Petroleum Engineering, Beijing, China, ${ }^{3}$ State Key Laboratory for Coal \\ Mine Disaster Dynamics and Control, Chongqing University, Chongqing, China
}

OPEN ACCESS

Edited by:

Yuwei Li,

Liaoning University, China

Reviewed by:

Tianshou Ma,

Southwest Petroleum University,

China

Bing Hou,

China University of Petroleum, China

Ada Huang,

University of Alberta, Canada

*Correspondence:

Zhenhui Bi

bzh199511998@163.com

Specialty section:

This article was submitted to

Economic Geology,

a section of the journal

Frontiers in Earth Science

Received: 16 August 2021

Accepted: 08 October 2021

Published: 16 November 2021

Citation:

Wang L, Bi Z, Zeng Y, Yang G, Guo Y and Yang $H$ (2021) Experimental Investigation on the Crack Evolution of

Marine Shale with Different

Soaking Fluids.

Front. Earth Sci. 9:759538.

doi: $10.3389 /$ feart.2021.759538
Hydration induced cracks could promote the complexity of hydraulic fractures in marine shale gas reservoir. But the evolution process and forming mechanism has not been fully investigated. In this paper, Longmaxi marine shale were collected and immersed in three types of fluids (distilled water, fracturing fluid, and mineral oil) for more than 10 days. The spatial-temporal evolution of soaking fractures was recorded and analyzed. A fracture mechanical model was established, considering the effects of in-situ stress, fluid pressure, hydration stress, and capillary force. The promotion mechanism of hydration cracks in forming complex fracking network was discussed. Results showed that hydration fractures were extremely developed and evenly distributed in a state of network for specimens immersed in distilled water. For specimens soaked in fracturing fluid, the hydration cracks were moderately developed for the addition of anti-swelling agent. Fractures were rarely developed for specimens treated in mineral oil. The hydration fractures were mainly formed in the first $5 \mathrm{~h}$ and showed strong anisotropy. Cracks parallel to the bedding planes accounted for the vast majority, with a small proportion developed in vertical direction. Theoretical calculations indicated that the stress intensity factor (SIF) caused by hydration stress and capillary force was greater than the measured fracture toughness. The micro crack would probably propagate along bedding planes and grow up into macro horizontal fractures, which promoted the formation of crisscrossing fracture network in shale gas formation.

Keywords: marine shale, hydration fracture, spatial-temporal evolution, fracture mechanical model, fracture network

\section{INTRODUCTION}

Marine organic-rich shales deposited in oceanic and continental margin basins are the most important source rocks of both conventional and unconventional oil and gas resources all over the world (Zou et al., 2019). During the past decade, marine shale gas exploration in China has acquired rapid progress. With the discovery of Fuling, Weiyuan, Changning, Fushun, Yongchuan

\footnotetext{
Abbreviations: $K_{I}^{(1)}$, Stress intensity factor (SIF) induced by in-situ stress $\mathrm{MPa}^{\bullet} \mathrm{m}^{1 / 2} ; \sigma$, Remote $i$-situ stress perpendicular to fracture face MPa; $a$ Half-length of the micro fracture $\mathrm{m} ; K_{I}^{(2)}$ SIF induced by fluid pressure $\mathrm{MPa} \bullet \mathrm{m}^{1 / 2} ; p_{f}$ Fluid pressure in fracture MPa; $b$ Half-length of infiltration area $\mathrm{m} . ; K_{I}^{(3)} \mathrm{SIF}$ induced by hydration stress $\mathrm{MPa} \bullet_{\mathrm{m}}^{1 / 2} ; \sigma_{w}$ Hydration stress MPa; $F$ Capillary force, $\mathrm{N} ; \gamma$ Surface tension of water $\mathrm{N} / \mathrm{m} ; \theta$ Contact angle ${ }^{\circ} ; W$ Fracture width $\mathrm{m} ; K_{I}^{(4)}$ SIF induced by capillary force $\mathrm{MPa} \bullet \mathrm{m}^{1 / 2} ; K_{I}$ Totality of SIF MPa $\bullet \mathrm{m}^{1 / 2} ; \sigma_{V}$ Vertical principal stress MPa; $\sigma_{h}$ Horizontal minimum principal stress MPa.
} 

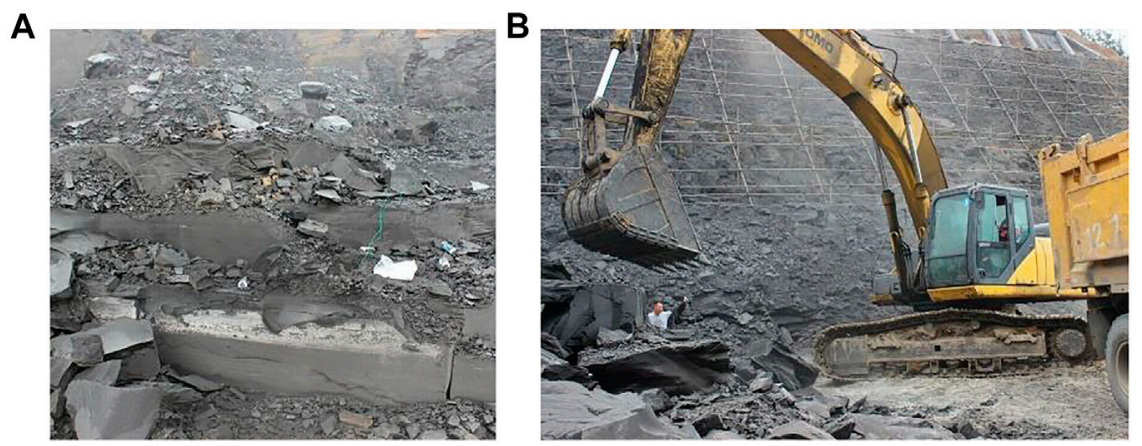

FIGURE 1 | Sampling process: (A) Longmaxi shale outcrop, and (B) field sampling.

Block in Sichuan Basin, the proved reserves of marine shale gas in China were up to 544.1 billion cubic meters, and the output of shale gas in 2020 reached 20 billion cubic meters (Cnr, 2021). Consequently, China has become the fourth country that achieved large scale commercial development of shale gas resources, and the other three countries are America, Canada and Argentina (Wang, 2017).

Shale hydration is a key factor that leads to wellbore instability problems in hard-brittle shale formation (Ma et al., 2021). Most researchers focused on revealing hydration mechanism (CHENEVERT ME, 1970; DARLEY HCH, 1969; Dokhani et al., 2015; Roshan et al., 2015; Wen et al., 2015; Liang et al., 2015; Kang et al., 2017) and developing effective anti-hydration drilling fluids to guarantee wellbore stability (Deville et al., 2011; Riley et al., 2012; An et al., 2015; Zhong et al., 2016; Barati et al., 2017). However, in the view of reservoir stimulation, it might be a positive effect on improving recovery ratio in shale gas reservoir (Dehghanpour et al., 2013; Ji and Geehan, 2013; Morsy and

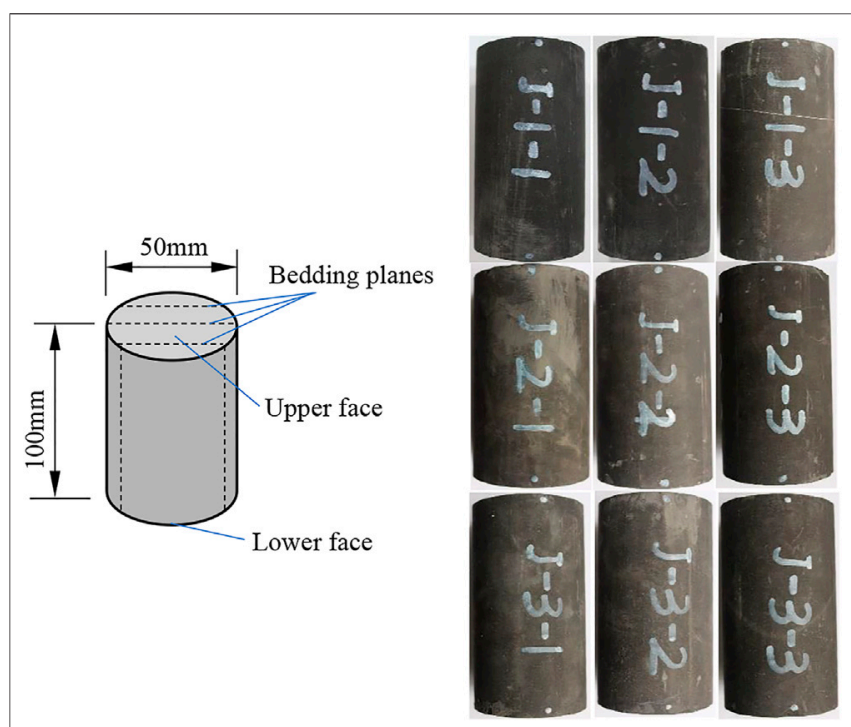

FIGURE 2 | Prepared standard specimens.
Sheng, 2014), because hydration induced fractures could enhance the formation permeability.

Field practice of shale gas exploration in Jiaoshiba block, Fuling Distict, Chongqing, China showed that it consumed about $3 \mathrm{~h}$ to fracturing one stage, preparation time between two adjacent stages was about $3-4 \mathrm{~h}$, so fracturing 2 stages would cost nearly 1 day. Supposing that a well needs to fracture 16 stages, 8 days were needed (Wang et al., 2017). Typically, during the whole process of hydraulic fracturing, tens of thousands cubic meter fluid were injected in the reservoir, with very small proportion returning to the ground (Yuyang et al., 2021). So, shale reservoir was in a state of fluid immersion environment and hydration process would fully develop. Zhang and Sheng (2017) studied of the propagation of hydration-induced fractures in Mancos shale using computerized tomography. Ma and Chen (2014) investigated on the mesodamage characteristics of shale hydration. However, previous studies mainly focused on the certain or final hydration state to evaluate hydration effect. The detailed spatial-temporal evolution process of hydration fractures in marine shale was rarely reported and still need systematic study, which was valuable for reservoir engineers to design more abundant and effective permeable fractures.

This paper presents a detailed study on the fracture evolution of Longmaxi marine shale, soaked in three different types of fluids. The distribution and total length of hydration fractures were observed and analyzed from the time of immersion to more than 10 days. A mechanical model, considering the effects of insitu stress, fluid pressure, hydration stress, and capillary force, was established to reveal the propagation mechanism of hydration fracture. Results could enlighten us about the formation mechanism of complex hydraulic fractures in shale gas reservoir.

\section{EXPERIMENTAL DESIGN}

\section{Sample Preparation}

The main shale gas reservoirs range from the upper Ordovician Wufeng Formation to lower Silurian Longmaxi Formation (Yi et al., 2019). Large shale blocks were collected from Longmaxi shale outcrop in Jiaoshiba Block, Fuling District, Chongqing, China (Figure 1). Then, cylindrical specimens with a diameter of 
TABLE 1 | Mineral composition and mechanical properties of sampled marine shale.

\begin{tabular}{|c|c|c|c|c|c|c|c|c|c|}
\hline \multicolumn{10}{|c|}{ Mineral composition } \\
\hline Mineral type & Quartz & Cristobalite & Albite & Calcite & Muscovite & Pyrite & Annite & Ankerite & Clay minera \\
\hline Content (\%) & 50.23 & 4.75 & 17.60 & 2.60 & 5.71 & 5.80 & 3.83 & 4.21 & 5.26 \\
\hline \multicolumn{10}{|c|}{ Mechanical properties } \\
\hline \multicolumn{3}{|c|}{ Loading direction VS Bedding plane } & \multicolumn{2}{|c|}{ Strength (MPa) } & \multicolumn{3}{|c|}{ Young's modulus (GPa) } & \multicolumn{2}{|c|}{ Poisson's ratio } \\
\hline \multicolumn{3}{|l|}{ Vertical } & \multicolumn{2}{|c|}{116.5} & \multicolumn{3}{|c|}{15.26} & \multicolumn{2}{|l|}{0.275} \\
\hline \multicolumn{3}{|l|}{ Horizontal } & \multicolumn{2}{|c|}{86.2} & \multicolumn{3}{|c|}{15.95} & \multicolumn{2}{|l|}{0.320} \\
\hline
\end{tabular}

TABLE 2 | Allocation of specimens according to three types of soaking fluids.

\begin{tabular}{|c|c|c|c|}
\hline Soaking fluids & Distilled water & Fracturing fluid & Mineral oil \\
\hline \multirow[t]{3}{*}{ Serial numbers of the specimens } & $\mathrm{J}-1-1$ & $\mathrm{~J}-2-1$ & $\mathrm{~J}-3-1$ \\
\hline & $\mathrm{J}-1-2$ & $\mathrm{~J}-2-2$ & $\mathrm{~J}-3-2$ \\
\hline & $J-1-3$ & $J-2-3$ & J-3-3 \\
\hline
\end{tabular}

$50 \mathrm{~mm}$ were cored from shale blocks with the direction parallel to the bedding plane. These cored cylinders were cut and polished into standard specimens $(\phi 50 \mathrm{~mm} \times 100 \mathrm{~mm}$ ) (Ulusay and Hudson, 2007). As shown in Figure 2, nine specimens were prepared ready for experiment. The mineral composition and general mechanical properties were provided in Table 1 (Guo et al., 2018).

\section{Experiment Scheme}

Three kinds of soaking fluids (distilled water, fracturing fluid, and mineral oil) were selected to study the crack induced by hydration in shale. Mineral oil is a kind of liquid that contains no water. So, hydration effect would not occur for specimens soaking in it, which could be regarded as a control group. The fracturing fluid was a kind of slick water applied on site, where some additives $(0.1 \%$ drag reducer, $0.2 \%$ anti-swelling agent, $0.1 \%$ synergistic agent, $0.02 \%$ anti-foaming agent) were added. MOBIL NUTO H46 was selected as mineral oil. As listed in Table 2, all nine specimens were divided into three groups and put into each of the three soaking fluids.

Test procedures are as follow:

1) Photograph the upper and lower faces of each specimen by high resolution camera to record the initial state of crack distribution.

2) Put each group of specimens into three vessels that contain different soaking fluids, guarantee all specimens are completely submerged.

3) After soaking for a certain time, take specimens out of the fluids and photograph the upper and lower faces of each specimen, then put specimens into the liquid again and keep on soaking. The time-points of taking out and photographing are set to $0,2,5,12$ and $23 \mathrm{~h}, 1 \mathrm{D} 01,1 \mathrm{D} 09,2 \mathrm{D} 09,4 \mathrm{D}, 7 \mathrm{D} 01$, 8D07 and 10D09 h from the test start time (h denotes hour, D represents day). The number of time-points are 12, and the whole observation period exceeds 10 days.

4) Import all photographs shot at different time-points into the AutoCAD software, draw and analyze the crack distribution of the upper and lower faces of all specimens.

\section{EXPERIMENTAL RESULT AND ANALYSIS}

\section{Crack Evolution \\ Soaking in Distilled Water}

After soaking in distilled water, the hydration fractures in the end faces of shale specimens were fully developed into a state of fracture network. Take the lower face of specimen J-1-2 for example (Figure 3). Before soaking, no fractures could be spotted by naked eyes. $2 \mathrm{~h}$ later, several fractures appeared parallel to the bedding planes. We called these horizontal fractures. After $5 \mathrm{~h}$, the preexisting fractures continued propagating and new fractures were also formed. It was worthwhile to note that a new fracture was approximately vertical to the bedding planes and link up two horizontal fractures. We called it vertical fracture. Fractures were spread all over the end face. In the subsequent period, hydration fractures developed in two patterns: propagating parallel to the bedding planes and fracturing perpendicular to the bedding planes. After soaking 10 days and $9 \mathrm{~h}(10 \mathrm{D} 09 \mathrm{~h})$, the end face of the specimen showed a state of crisscrossing fracture network.

\section{Soaking in Fracturing Fluid}

For specimens soaking in fracturing fluid, hydration fractures were developed moderately and mainly paralleled to the bedding planes. Take the lower face of specimen J-2-3 for example (Figure 4). Originally, there were no obvious fractures in the end face. After soaking $2 \mathrm{~h}$, several horizontal fractures were formed in the middle and lower part of the surface. Although continue soaking, rare new fractures were formed in other regions, instead, preexisting fractures kept on propagating and branching. Because of the addition of antiswelling agent in fracturing fluid, the free swelling of clay minerals was restrained, leading to the relatively moderately developed hydration fractures compared with that immersed in distilled water.

\section{Soaking in Mineral Oil}

Entirely different from the specimens immersed in distilled water and fracturing fluid, fractures were rarely developed for specimens soaking in mineral oil. Take the specimen J-3-2 for 

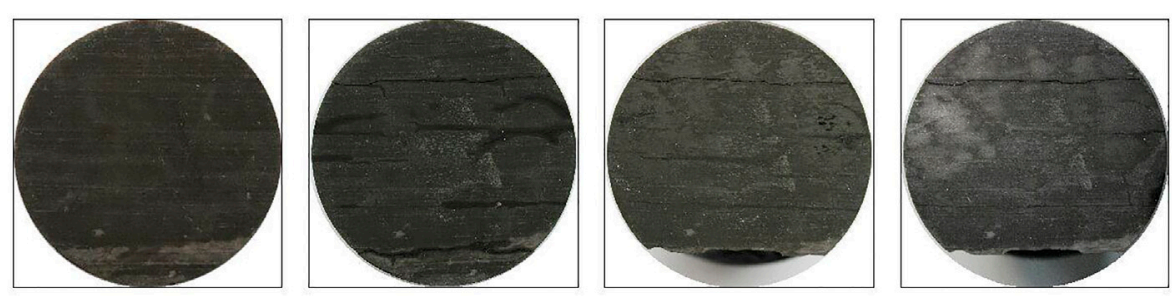

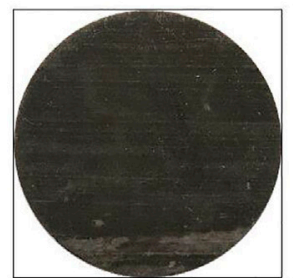

Initial
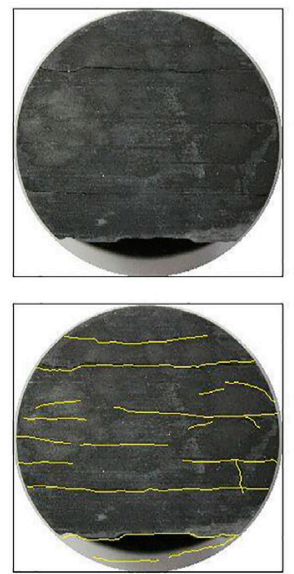

$23 h$
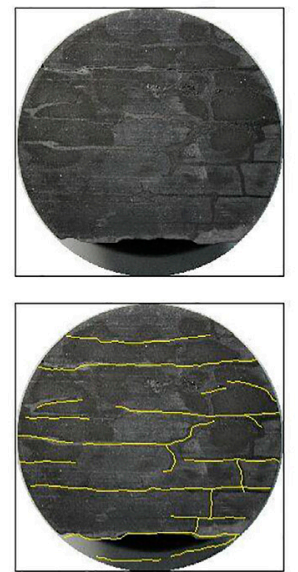

4D

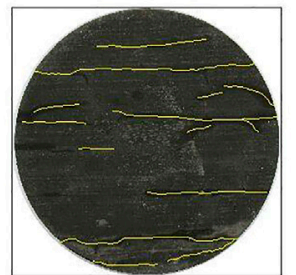

$2 \mathrm{~h}$
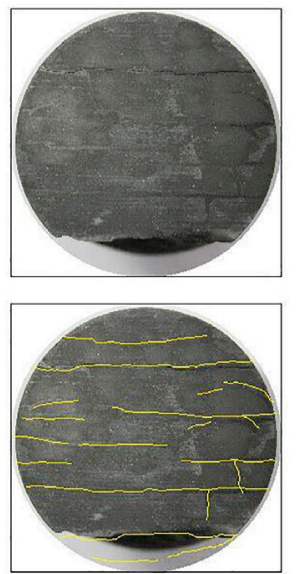

1D01h
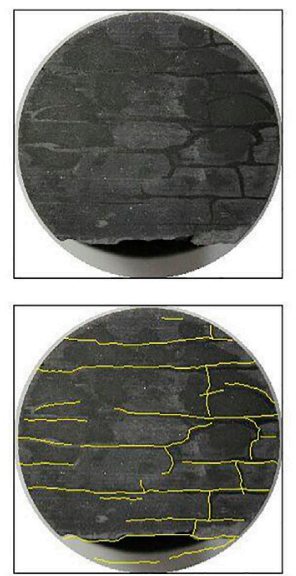

7D01h

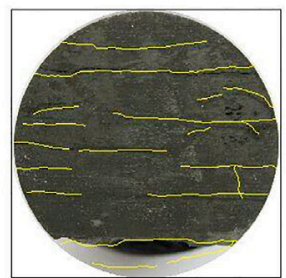

$5 \mathrm{~h}$
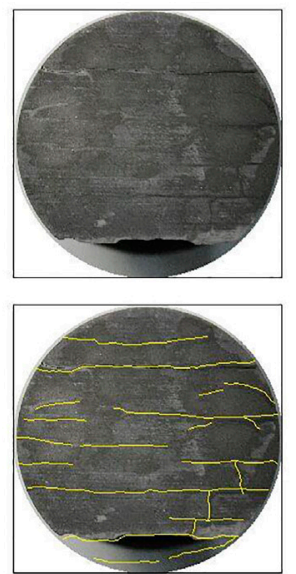

1D09h
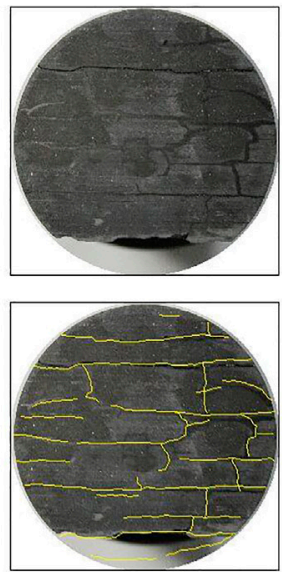

$8 \mathrm{D} 07 \mathrm{~h}$

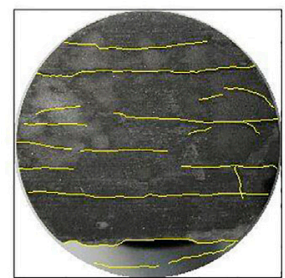

$12 \mathrm{~h}$
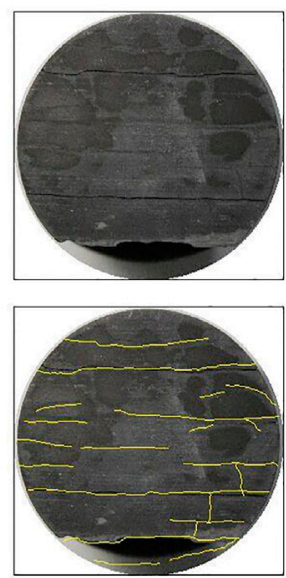

2D09h
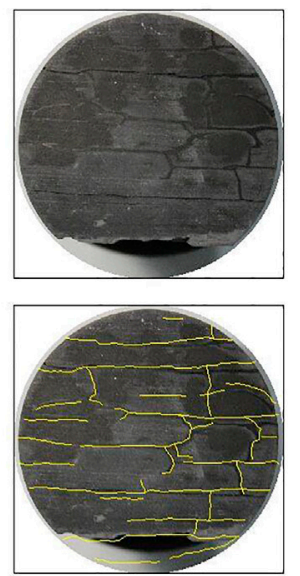

10D09h

FIGURE 3 | Crack evolution process in distilled water (lower face of $\mathbf{J - 1 - 2}$ ) (In first line, original photos were showed; in second line, hydration fractures were highlighted by yellow lines in original photos). 

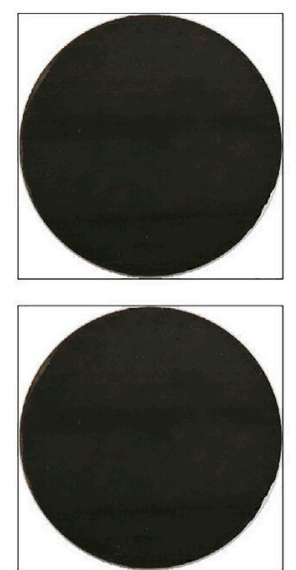

Initial
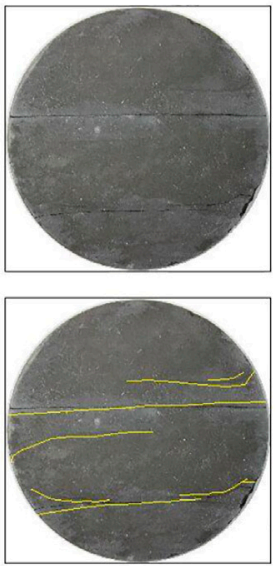

$23 \mathrm{~h}$
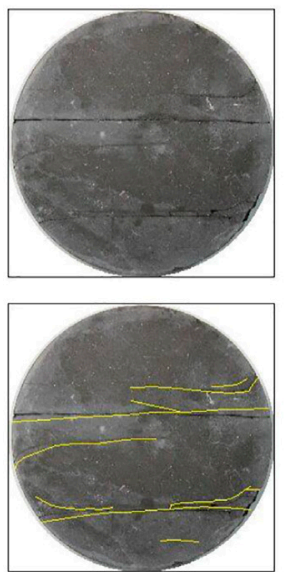

4D
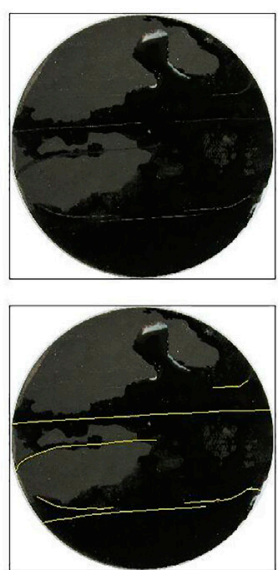

$2 \mathrm{~h}$
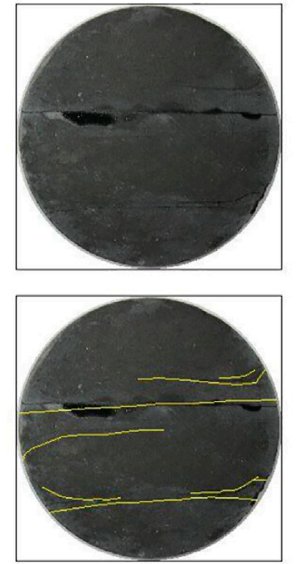

1D01h
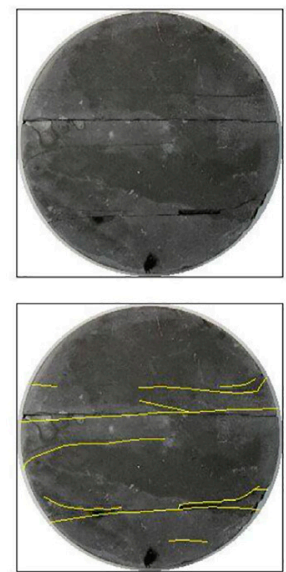

7D01h
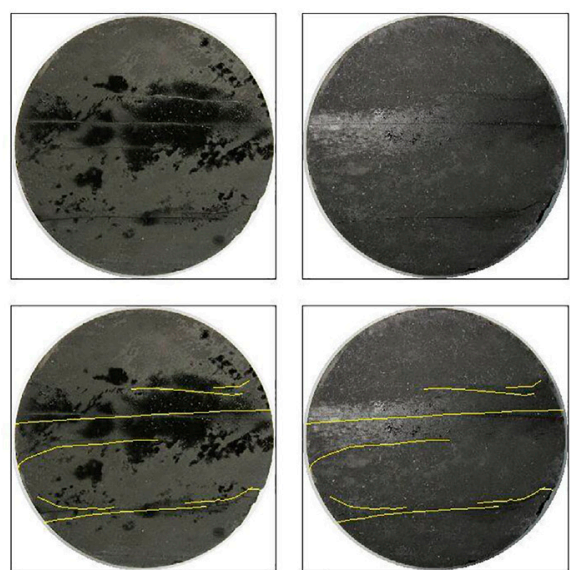

$5 \mathrm{~h}$

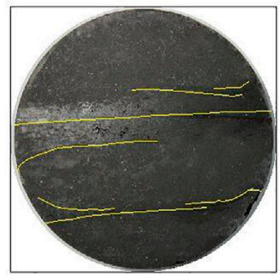

$12 \mathrm{~h}$
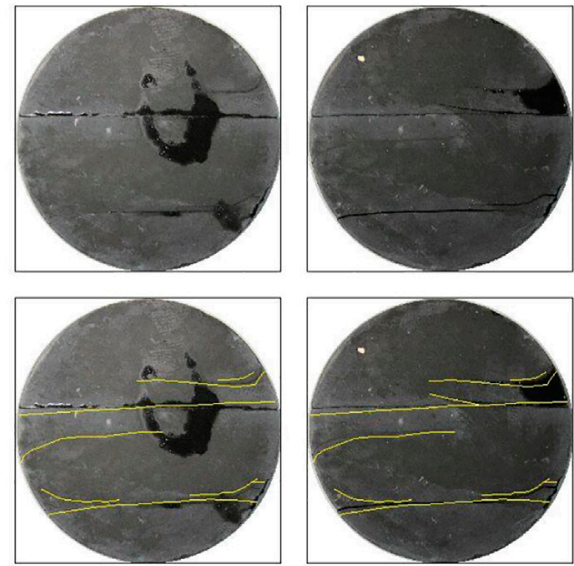

1D09h

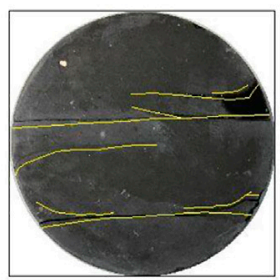

2D09h
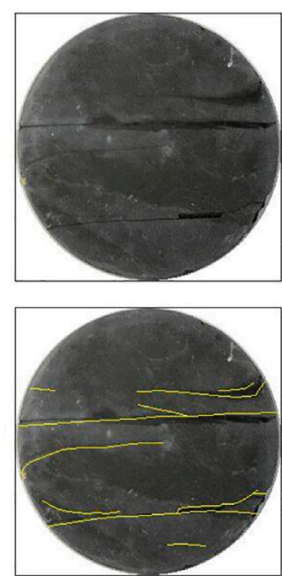

8D07h
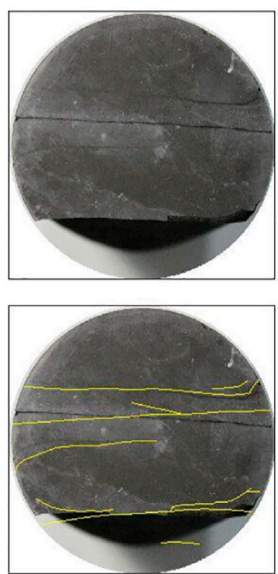

10D09h

FIGURE 4 | Crack evolution process in fracturing fluid (lower face of $\mathbf{J - 2 - 3}$ )

example (Figure 5). There was one fracture in the upper face before soaking. After soaking $10 \mathrm{D} 09 \mathrm{~h}$, only one fracture developed in the middle part of the section and failed to reach the border. For the lower face, no fractures were spotted before test, and only three small fractures were formed after soaking 10D09 h. 

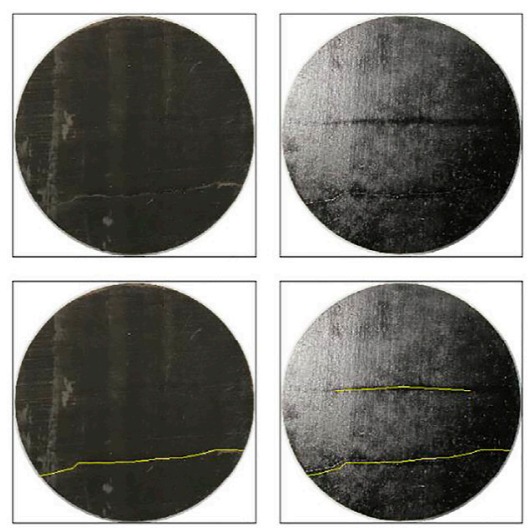

10D09h
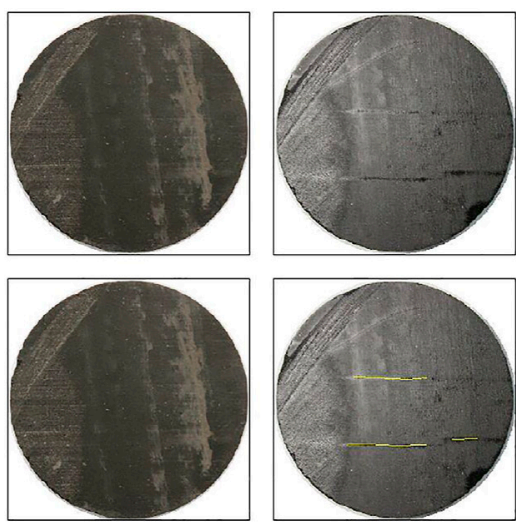

Initial

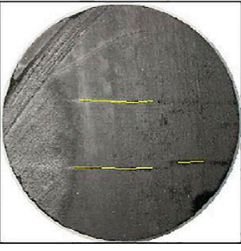

$10 \mathrm{D} 09 \mathrm{~h}$

Upper face

Lower face

FIGURE 5 | Crack evolution process in mineral oil (J-3-2).

TABLE 3 | Statistics of length of all hydration crack of specimens soaking in distilled water and fracturing fluid (Unit: $\mathrm{mm}$ ).

\begin{tabular}{|c|c|c|c|c|c|c|c|c|c|c|c|c|c|}
\hline \multicolumn{2}{|c|}{$\begin{array}{l}\text { Time points } \\
\text { number }\end{array}$} & \multirow{2}{*}{$\begin{array}{c}\mathbf{O h} \\
0\end{array}$} & \multirow{2}{*}{$\begin{array}{l}2 \mathbf{h} \\
128\end{array}$} & \multirow{2}{*}{$\begin{array}{l}5 \mathbf{h} \\
128\end{array}$} & \multirow{2}{*}{$\begin{array}{l}12 \text { h } \\
144\end{array}$} & \multirow{2}{*}{$\begin{array}{c}23 \text { h } \\
144\end{array}$} & \multirow{2}{*}{$\begin{array}{c}\text { 1D01 h } \\
147\end{array}$} & \multirow{2}{*}{$\begin{array}{c}\text { 1D09 h } \\
147\end{array}$} & \multirow{2}{*}{$\begin{array}{c}\text { 2D09 h } \\
226\end{array}$} & \multirow{2}{*}{$\begin{array}{l}\text { 4D } \\
226\end{array}$} & \multirow{2}{*}{$\begin{array}{c}\text { 7D01 h } \\
229\end{array}$} & \multirow{2}{*}{$\begin{array}{c}\text { 8D07 h } \\
229\end{array}$} & \multirow{2}{*}{$\frac{\text { 10D09 h }}{229}$} \\
\hline$J-1-1$ & Upper & & & & & & & & & & & & \\
\hline & Lower & 0 & 163 & 163 & 210 & 215 & 216 & 216 & 230 & 306 & 331 & 337 & 340 \\
\hline \multirow[t]{2}{*}{$J-1-2$} & Upper & 0 & 106 & 119 & 128 & 140 & 140 & 163 & 188 & 190 & 190 & 202 & 205 \\
\hline & Lower & 0 & 223 & 295 & 308 & 308 & 313 & 330 & 330 & 342 & 390 & 404 & 420 \\
\hline \multirow[t]{2}{*}{$J-1-3$} & Upper & 0 & 189 & 207 & 218 & 225 & 225 & 225 & 269 & 276 & 292 & 292 & 301 \\
\hline & Lower & 49 & 193 & 237 & 237 & 258 & 258 & 266 & 281 & 287 & 287 & 293 & 301 \\
\hline \multirow[t]{2}{*}{$J-2-1$} & Upper & 11 & 169 & 186 & 186 & 186 & 186 & 186 & 211 & 211 & 214 & 214 & 214 \\
\hline & Lower & 0 & 233 & 245 & 258 & 262 & 274 & 274 & 274 & 276 & 276 & 282 & 282 \\
\hline \multirow[t]{2}{*}{ J-2-2 } & Upper & 30 & 207 & 211 & 232 & 239 & 239 & 239 & 263 & 264 & 268 & 271 & 271 \\
\hline & Lower & 23 & 191 & 233 & 233 & 248 & 251 & 251 & 255 & 259 & 259 & 266 & 266 \\
\hline \multirow[t]{2}{*}{$J-2-3$} & Upper & 0 & 145 & 166 & 166 & 170 & 179 & 179 & 188 & 199 & 203 & 203 & 219 \\
\hline & Lower & 49 & 76 & 129 & 142 & 145 & 145 & 155 & 163 & 163 & 163 & 179 & 181 \\
\hline
\end{tabular}
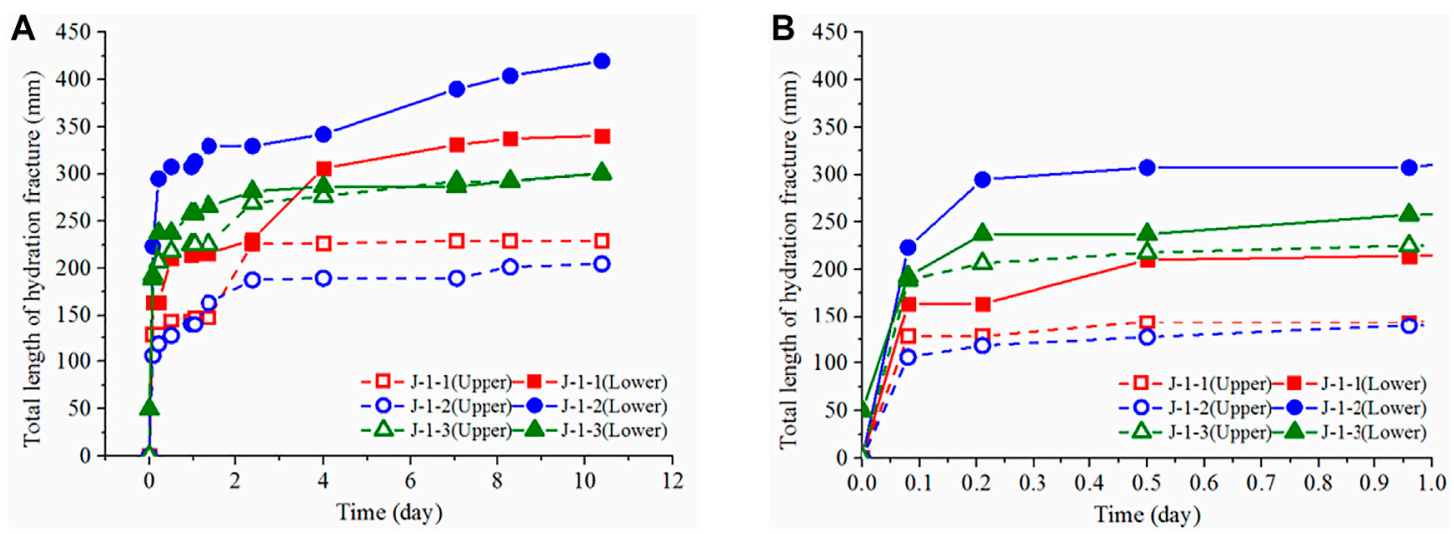

FIGURE 6 | Increase of the length of hydration fractures soaking in distilled water with time: (A) complete period, and (B) the first day. 

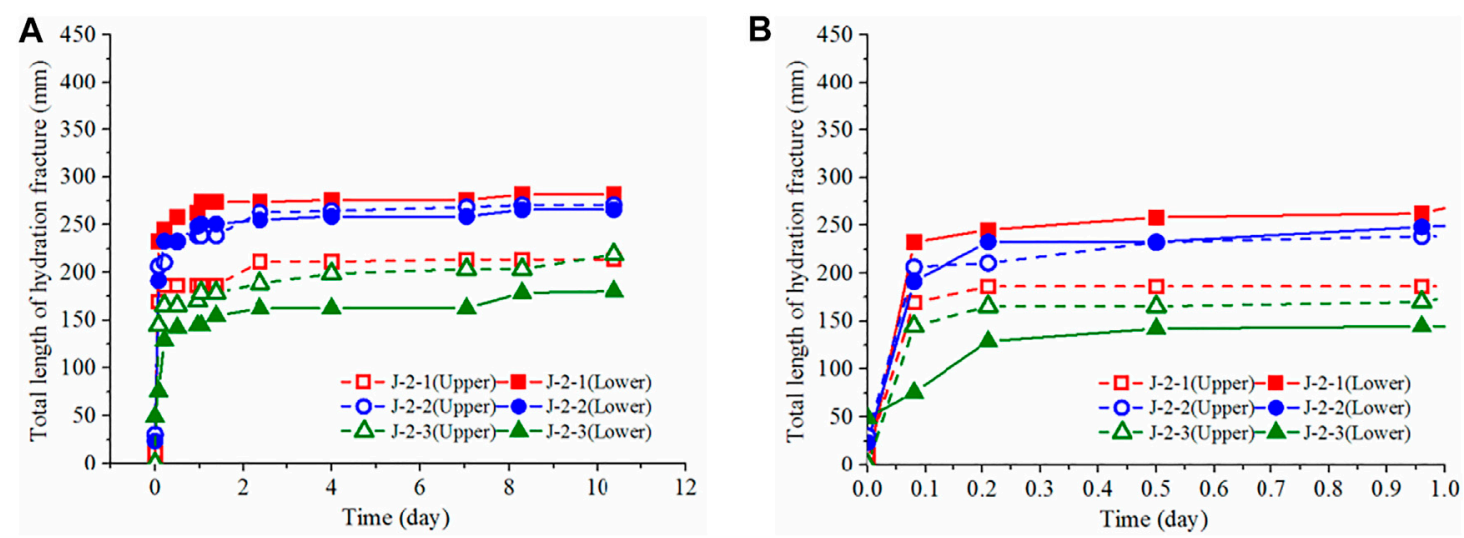

FIGURE 7 | Increase of the length of hydration fractures soaking in fracturing fluid with time: (A) complete period, and (B) the first day.

TABLE 4 | Statistics of length of vertical hydration crack of specimens soaking in purified water and fracturing fluid (Unit: mm).

\begin{tabular}{|c|c|c|c|c|c|c|c|}
\hline \multirow[t]{2}{*}{ Number } & & \multirow[t]{2}{*}{ Soaking fluids } & \multicolumn{3}{|c|}{ Vertical fractures } & \multirow{2}{*}{$\begin{array}{l}\text { Total length of all } \\
\text { fractures }\end{array}$} & \multirow{2}{*}{$\begin{array}{c}\text { Proportion of vertical } \\
\text { fractures }\end{array}$} \\
\hline & & & Whether occur & Occurrence time & Length & & \\
\hline \multirow[t]{2}{*}{$J-1-1$} & Upper & Distilled water & No & --- & --- & 229 & --- \\
\hline & Lower & & Yes & 2D09 h & 37 & 340 & $11 \%$ \\
\hline \multirow[t]{2}{*}{ J-1-2 } & Upper & & No & --- & --- & 205 & --- \\
\hline & Lower & & Yes & $5 \mathrm{~h}$ & 56 & 420 & $13 \%$ \\
\hline \multirow[t]{2}{*}{$J-1-3$} & Upper & & Yes & $23 \mathrm{~h}$ & 23 & 301 & $8 \%$ \\
\hline & Lower & & Yes & $4 \mathrm{D}$ & 11 & 301 & $4 \%$ \\
\hline \multirow[t]{2}{*}{ J-2-1 } & Upper & Fracturing fluid & No & --- & --- & 214 & --- \\
\hline & Lower & & No & --- & --- & 282 & --- \\
\hline \multirow[t]{2}{*}{$\mathrm{J}-2-2$} & Upper & & No & --- & --- & 271 & --- \\
\hline & Lower & & Yes & 2D09 h & 9 & 266 & $3 \%$ \\
\hline \multirow[t]{2}{*}{ J-2-3 } & Upper & & No & --- & --- & 219 & --- \\
\hline & Lower & & No & --- & --- & 181 & --- \\
\hline
\end{tabular}

\section{Statistical Analysis of Hydration Fractures Evolution of the Total Fracture Length}

The total length of end face hydration fractures at each soaking time-points were measured in AutoCAD. All data were collected in Table 3. Considering only a few fractures were formed in specimens submerging in mineral oil, fractures in these specimens were not included here.

For specimens soaking in distilled water, the length of hydration fractures grew rapidly in the early $5 \mathrm{~h}$, then slowed down, and gradually reached a plateau. Finally, the total length of hydration fractures distributed between 150 and $450 \mathrm{~mm}$ (Figure 6). The average value of the six end faces was $299 \mathrm{~mm}$. This indicated that the major part of hydration fractures was formed in the early period.

As illustrated in Figure 7, the evolution of the length of hydration fractures soaking in fracturing fluid was similar to those submerging in distilled water. The length of hydration fractures grew rapidly in the early $5 \mathrm{~h}$, then slowed down, and finally became stable. The final hydration fracture length was distributed between 150 and $300 \mathrm{~mm}$. The average value of the six end faces was $239 \mathrm{~mm}$, decreased by $20 \%$ compared with that soaking in distilled water.

\section{Evolution of the Vertical Fractures}

It is worth considering that vertical fractures (fractures perpendicular to bedding planes) developed in some end faces of specimens and made the fracture system more complicated. Therefore, it was valuable to count and analyze the evolution of vertical fractures. Statistical data of vertical fractures were listed in Table 4. For specimens soaking in distilled water, four out of six end faces developed vertical fractures and the total fracture length were greater than those not forming vertical fractures. For specimens submerging in fracturing fluid, only one out of six end faces developed vertical fractures. The occurrence time of vertical fractures distributed between $5 \mathrm{~h}$ and 4 days. The proportion of length of vertical fractures was $3-13 \%$, which was relatively small.

\section{PROPAGATING MODEL OF THE HYDRATION FRACTURE}

By investigating microstructure change during shale hydration, Shi et al. (2012) argued that capillary force induced by microfractures in shale promoted the hydration of clay 


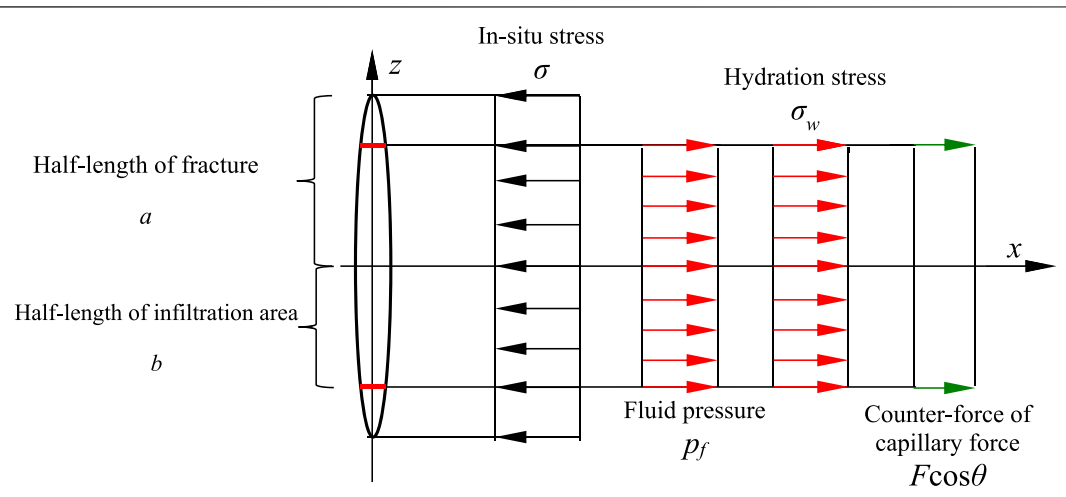

FIGURE 8 | Force analysis of hydration fracture.

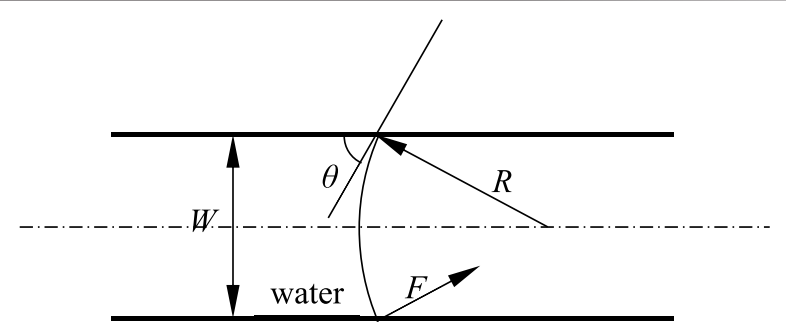

FIGURE 9 | Force analysis of capillary effect.

mineral. Meanwhile, hydration in turn accelerated the propagation of microfractures. This mutual promotion mechanism leads to the rapid evolution of hydration cracks. For this reason, a fracture propagation model considering hydration and capillary effect were established based on the theory of fracture mechanics (Anderson, 2005), and the promoting mechanism of hydration and capillary effect to fracture propagation were analyzed in a mechanical view.

The mechanical model is based on the following assumptions:

1) An infinite homogeneous medium contains a finite fracture;

2) The medium behaves in a linear elastic response to loading;

3) The fracture width is small enough to cause notable capillary effects;

4) Fluid pressure and hydration stress both distribute uniformly along fracture surface.

By considering hydration and capillary effects, the stress intensity factor (SIF) at fracture tip is determined by remote in-situ stress, fluid pressure, hydration stress and capillary force (see Figure 8).

1) SIF induced by in-situ stress

$$
K_{I}^{(1)}=-\sigma \sqrt{\pi a}
$$

Where $\sigma$ is the remote in-situ stress perpendicular to fracture face, $\mathrm{MPa} ; a$ is the half length of the micro fracture, $\mathrm{m}$.
2) SIF induced by fluid pressure

$$
K_{I}^{(2)}=2 p_{f} \sqrt{\frac{a}{\pi}} \arcsin \frac{b}{a}
$$

Where $p_{f}$ is the fluid pressure in fracture, $\mathrm{MPa} ; b$ is the half length of infiltration area, $\mathrm{m}$.

3) SIF induced by hydration stress

Hydration force are the result of swelling of clay mineral. Assume the clay mineral is distributed evenly in shale, and the hydration stress $\sigma_{w}$ spread uniformly in fracture surface, the model I SIF can be described by

$$
K_{I}^{(3)}=2 \sigma_{w} \sqrt{\frac{a}{\pi}} \arcsin \frac{b}{a}
$$

4) SIF induced by capillary force

By simplifying the micro-fracture faces as parallel-plate, capillary force could be calculated by

$$
F=\frac{2 \gamma \cos \theta}{W}
$$

Where $F$ is capillary force, $\mathrm{N} ; \theta$ is contact angle, ${ }^{\circ} ; W$ is fracture width, $\mathrm{m} ; \gamma$ is surface tension of water, $\mathrm{N} / \mathrm{m}$ (Figure 9).

Fracture surface would bear the counter force of capillary force, $F \cos \theta$. SIF induced by this counter force is

$$
K_{I}^{(4)}=\frac{4 \gamma \cos ^{2} \theta}{W} \sqrt{\frac{a}{\pi a^{2}-b^{2}}}
$$

The superposition of the above 4 parts results in the final mode I SIF.

$$
\begin{aligned}
& K_{I}=K_{I}^{(1)}+K_{I}^{(2)}+K_{I}^{(3)}+K_{I}^{(4)} \\
& =-\sigma \sqrt{\pi a}+2 p_{f}+\sigma_{w} \sqrt{\frac{a}{\pi}} \arcsin \frac{b}{a}+\frac{4 \gamma \cos ^{2} \theta}{W} \sqrt{\frac{a}{\pi a^{2}-b^{2}}}
\end{aligned}
$$




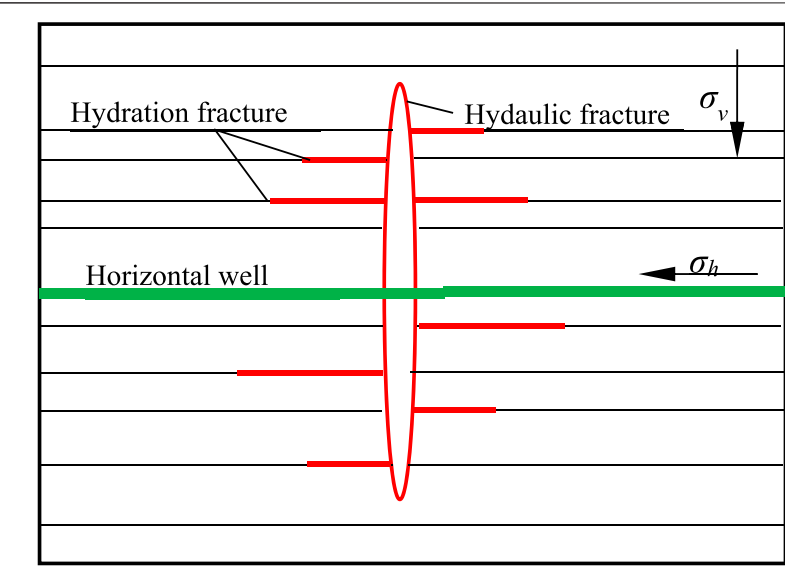

FIGURE 10 | Influence of hydration fracture to hydraulic fracturing.

Without considering the influence of in-situ stress and fluid pressure, assume the half length of micro-fracture is $0.005 \mathrm{~m}$, half-length of infiltration area is $0.004 \mathrm{~m}$, fracture with is $0.001 \mathrm{~m}$, contact angle is $15^{\circ}$, surface tension is $0.0728 \mathrm{~N} / \mathrm{m}$, hydration stress is $1 \mathrm{MPa}$, the SIF induced by hydration and capillary effects is $3.613 \mathrm{MPa} \mathrm{m}^{1 / 2}$. Heng et al. (2015) got the fracture toughness of shale $\left(0.566 \mathrm{MPa} \mathrm{m}^{1 / 2}\right.$ along the bedding plane and $1.146 \mathrm{MPa} \mathrm{m}^{1 / 2}$ perpendicular the bedding plane) by performing three-point bending test. By comparing this with previous study, it is apparently that the SIF caused by hydration stress and capillary force is greater than the measured fracture toughness and the micro-fracture would probably propagate.

\section{DISCUSSION}

Fracture propagation caused by hydration might play a key role in the formation of fracture network in shale gas extraction. As the major hydraulic fracture extends in the vertical or transverse direction, hydration fracture would form along the direction of bedding plane in the face of fracture. High fluid pressure and capillary induced hydration effect promotes fracture propagation along bedding-plane to the deeper shale reservoir. Micro hydration fracture would gradually develop into macro-crack which is a part of the whole hydraulic fractures. Finally, a 3-D stimulated volume would form, where major hydraulic fractures propagate along the direction of fracture height and length and secondary fractures extend along the direction of bedding planes (Figure 10).

Another import change is the reservoir stiffness. Shale formation that has been hydro-fractured is no longer an intact rock mass. Its strength, Youngs Modulus would reduce to some extent, and the permeability might increase. All these would bring critical influence on the follow-up fracturing and refracturing Wang et al., 2020.

It is a very interesting phenomenon that vertical cracks (fractures perpendicular to the bedding planes) occurred with horizontal (along bedding) fractures. Further analysis indicated that the occurrence time of vertical fractures distributed between $5 \mathrm{~h}$ and 4 days, at which the horizontal fractures had already been fully developed. It seems the horizontal and vertical fractures appeared in chronological order. As shown in Figure 11, the clay minerals usually arranged directionally along shale bedding planes. During the initial hydration process, the water absorption of clay minerals could induce great swelling stress to open the bedding planes. So, horizontal fractures along bedding planes would occur first and fully develop. Furthermore, the fully developed horizontal cracks promoted continuous hydration and swelling of clay minerals. This process could produce tensile stress along horizontal fracture surface and then induce the crack initiation and propagation perpendicular to the bedding planes, which contributed to forming the vertical cracks.

The application of water based fracturing fluid could induce abundant hydration cracks to increase the fracture complexity of fracking. But complex fractures would not surely represent high conductivity. The permeability damage caused by the swelling of clay mineral should also be evaluated, which is one of the critical disadvantages of the application of water based fracturing fluid Cong et al., 2022. Extra permeability tests should be conducted. The ideal water based fracturing fluid should not only create complex fractures, but also keep good fracture conductivity.

Although the evolution of hydration cracks was studied in this experiment, several limitations should be clarified to guide future research. Firstly, the test was conducted at room temperature and pressure, which ignored the high temperature and high pressure formation environment (Wang et al., 2021). Secondly, we only described the surface crack evolution, and failed to present the crack propagation inside the sample, which could be revealed by CT scanning (Ma and Chen, 2014; (Ma et al., 2016; Zhang and Sheng, 2017). Finally, the anisotropic bedding structure of shale

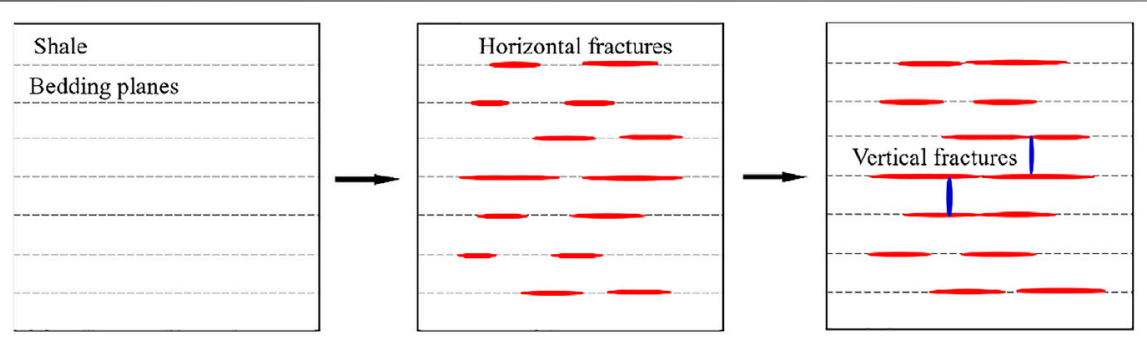

FIGURE 11 | Sketch map of the evolution of hydration fractures. 
was not considered in theoretical analysis (Gui et al., 2018; (Ma et al., 2021). Restricted to experiment condition, the above aspects were not realized and would be paid attention in future study.

\section{CONCLUSION}

Shale hydration fractures not only threaten wellbore stability, but also influence the effect of reservoir stimulation. By performing shale soaking experiment in three different fluids, conclusions are as follows:

1) For specimens soaking in distilled water, hydration fractures were extremely developed and evenly distributed in a state of network, and their final average cumulative length were $299 \mathrm{~mm}$.

2) For specimens soaking in fracturing fluid, hydration fractures were moderately developed and local accumulated, the final average cumulative length were $239 \mathrm{~mm}$. The addition of antiswelling agent remarkably restrained the free swelling of clay minerals. Fractures were rarely developed for specimens soaking in mineral oil.

3) The hydration fractures were mainly formed in the first $5 \mathrm{~h}$ and showed strong anisotropy. Cracks parallel to the bedding plane accounted for the vast majority, with a small proportion developed in vertical direction.

4) Theoretical calculations indicated that the stress intensity factor (SIF) caused by hydration stress and capillary force

\section{REFERENCES}

An, Y., Jiang, G., Ren, Y., Zhang, L., Qi, Y., and Ge, Q. (2015). An Environmental Friendly and Biodegradable Shale Inhibitor Based on Chitosan Quaternary Ammonium Salt. J. Pet. Sci. Eng. 135, 253-260. doi:10.1016/j.petrol.2015.09.005

Anderson, T. L. (2005). Fracture Mechanics-Fundamentals and Applications. Boca Raton: CRC Press.

Barati, P., Shahbazi, K., Kamari, M., and Aghajafari, A. (2017). Shale Hydration Inhibition Characteristics and Mechanism of a New Amine-Based Additive in Water-Based Drilling Fluids. Petroleum 3, 476-482. doi:10.1016/ j.petlm.2017.05.003

CHENEVERT ME (1970). Shale Alteration by Water Adsorption. J. Pet. Tech. 22, 1141-1148. doi:10.2118/2401-pa

Cnr (2021). The Growth Rate of Shale Gas Production in China Exceeded 30\% in 2020. Available at: http://baijiahao.baidu.com/s? id $=1691230280447523341 \& w f r=s p i d e r \&$ for $=$ pc.

Cong, Z., Li, Y., Pan, Y., Liu, B., Shi, Y., and Wei, J. (2022). Study on CO2 foam fracturing model and fracture propagation simulation. Energy 338, 121778. doi:10.1016/j.energy.2021.121778

DARLEY HCH (1969). A Laboratory Investigation of Borehole Stability. J. Pet. Tech. 21, 883-892. doi:10.2118/2400-pa

Dehghanpour, H., Lan, Q., Saeed, Y., Fei, H., and Qi, Z. (2013). Spontaneous Imbibition of Brine and Oil in Gas Shales: Effect of Water Adsorption and Resulting Microfractures. Energy Fuels 27, 3039-3049. doi:10.1021/ef4002814

Deville, J. P., Fritz, B., and Jarrett, M. (2011). Development of Water-Based Drilling Fluids Customized for Shale Reservoirs. SPE Drilling and Completion 26, 484-491. doi:10.2118/140868-PA

Dokhani, V., Yu, M., Takach, N. E., and Bloys, B. (2015). The Role of Moisture Adsorption in Wellbore Stability of Shale Formations: Mechanism and Modeling. J. Nat. Gas Sci. Eng. 27, 168-177. doi:10.1016/j.jngse.2015.08.056

Gui, J., Ma, T., Chen, P., Yuan, H., and Guo, Z. (2018). Anisotropic Damage to Hard Brittle Shale with Stress and Hydration Coupling. Energies 11, 1-15. doi:10.3390/en11040926 was greater than the measured fracture toughness. The micro crack would probably propagate along bedding plane and grow up into macro horizontal fractures, which promoted the formation of crisscrossing fracture network in shale gas formation

\section{DATA AVAILABILITY STATEMENT}

The original contributions presented in the study are included in the article/Supplementary Material, further inquiries can be directed to the corresponding author.

\section{AUTHOR CONTRIBUTIONS}

LW: Formal analysis; Writing-original draft. ZB: Writing-review and; editing. YZ: Acquisition and analysis of data. GY: Data curation. YG: Conceptualization; Methodology. HY: Design of the experiment.

\section{FUNDING}

This work was sponsored by the "Sinopec Science and Technology Department Project” (P21056). The open access publication fees is provided by this fund.

Guo, Y., Yang, C., Wang, L., and Xu, F. (2018). Effects of Cyclic Loading on the Mechanical Properties of Mature Bedding Shale. Adv. Civil Eng. 2018, 9. doi:10.1155/2018/8985973

Heng, S., Yang, C., Guo, Y., Wang, C., and Wang, L. (2015). Influence of Bedding Planes on Hydraulic Fracture Propagation in Shale Formations. Chin. J. Rock Mech. Eng. 34, 228-237. doi:10.13722/j.cnki.jrme.2015.02.002

Ji, L., and Geehan, T. (2013). "Shale Failure Around Hydraulic Fractures in Water Fracturing of Gas Shale," in SPE Canadian Unconventional Resources Conference 2013 - Unconventional Becoming Conventional: Lessons Learned and New Innovations (Calgary, Alberta, Canada: Society of Petroleum Engineers), 406-416. doi:10.2118/167155-ms

Kang, Y., Yang, B., Li, X., Yang, J., You, L., and Chen, Q. (2017). Quantitative Characterization of Micro Forces in Shale Hydration and Field Applications. Pet. Exploration Develop. 44, 328-335. doi:10.1016/S1876-3804(17)30038-1

Liang, L., Xiong, J., and Liu, X. (2015). Experimental Study on Crack Propagation in Shale Formations Considering Hydration and Wettability. J. Nat. Gas Sci. Eng. 23, 492-499. doi:10.1016/j.jngse.2015.02.032

Ma, T., and Chen, P. (2014). Study of Meso-Damage Characteristics of Shale Hydration Based on CT Scanning Technology. Pet. Exploration Develop. 41, 249-256. doi:10.1016/S1876-3804(14)60029-X

Ma, T., Gui, J., and Chen, P. (2021). Logging Evaluation on Mechanical-Damage Characteristics of the Vicinity of the Wellbore in Tight Reservoirs. J. Petrol. Explor Prod. Technol. 11, 3213-3224. doi:10.1007/s13202-021-01200-7

Ma, T., Yang, C., Chen, P., Wang, X., and Guo, Y. (2016). On the Damage Constitutive Model for Hydrated Shale Using CT Scanning Technology. J. Nat. Gas Sci. Eng. 28, 204-214. doi:10.1016/j.jngse.2015.11.025

Morsy, S., and Sheng, J. J. (2014). Effect of Water Salinity on Shale Reservoir Productivity. Adv. Pet. Exploration Develop. 8, 9-14. doi:10.3968/5604

Riley, M., Stamatakis, E., Young, S., Price Hoelsher, K., De Stefano, G., Ji, L., Guo, Q., and Friedheim, J. (2012). "Wellbore Stability in Unconventional Shale - The Design of a Nano-Particle Fluid," in Oil and Gas India Conference and Exhibition 2012, OGIC - Further, Deeper, Tougher: The Quest Continues. (Mumbai, India: Society of Petroleum Engineers - SPE), 416-423. doi:10.2118/ 153729-ms 
Roshan, H., Ehsani, S., Marjo, C. E., Andersen, M. S., and Acworth, R. I. (2015). Mechanisms of Water Adsorption into Partially Saturated Fractured Shales: An Experimental Study. Fuel 159, 628-637. doi:10.1016/ j.fuel.2015.07.015

Shi, B., Xia, B., Lin, Y., and Xu, J. (2012). CT Imaging and Mechanism Analysis of Crack Development by Hydration in Hard-Brittle Shale Formations. Acta Petrolei Sinica 33, 137-142.

Ulusay, R., and Hudson, J. A. (2007). The Complete ISRM Suggested Methods for Rock Characterization, Testing and Monitoring; 1974-2006. Cham, Switzerland: International Society for Rock Mechanics.

Wang, L., Guo, Y., Zhou, J., Yang, H., Yang, C., and Xiao, J. (2021). Rock Mechanical Characteristics of Deep marine Shale in Southern China, a Case Study in Dingshan Block. J. Pet. Sci. Eng. 204, 108699. doi:10.1016/ j.petrol.2021.108699

Wang, L., Tang, K., Chen, F., Guo, T., Ren, G., and Dai, C. (2017). Technology of Bridge Plug and Multi-cluster Perforation and Its Application in Shale Gas of Sichuan and Chongqing Area. Well Logging Technol 41, 373-377.

Wang, S., Sun, D., Du, W., Geng, B., Bai, R., and Wang, Y. (2020). Evaluation Method of Shale Brittleness Index. Well Logging Technol 44, 294-299. doi:10.16489/j.issn.1004-1338.2017.03.023

Wang, S. (2017). Shale Gas Exploitation: Status, Issues and Prospects. Nat. Gas Industry 37, 115-130. doi:10.3787/j.issn.1000-0976.2017.06.016

Wen, H., Chen, M., Jin, Y., Zhang, Y., Ge, W., Du, J., et al. (2015). Water Activity Characteristics of Deep Brittle Shale from Southwest China. Appl. Clay Sci. 108, 165-172. doi:10.1016/j.clay.2015.02.015

Yi, J., Bao, H., Zheng, A., Zhang, B., Shu, Z., Li, J., et al. (2019). Main Factors Controlling marine Shale Gas Enrichment and High-Yield wells in South China: A Case Study of the Fuling Shale Gas Field. Mar. Pet. Geology. 103, 114-125. doi:10.1016/j.marpetgeo.2019.01.024

Yuyang, L., Xinhua, M., Xiaowei, Z., Wei, G., Lixia, K., Rongze, Y., et al. (2021). Shale Gas Well Flowback Rate Prediction for Weiyuan Field Based on a Deep
Learning Algorithm. J. Pet. Sci. Eng. 203, 108637. doi:10.1016/ j.petrol.2021.108637

Zhang, S., and Sheng, J. J. (2017). Study of the Propagation of Hydration-Induced Fractures in mancos Shale Using Computerized Tomography. Int. J. Rock Mech. Mining Sci. 95, 1-7. doi:10.1016/j.ijrmms.2017.03.011

Zhong, H., Qiu, Z., Zhang, D., Tang, Z., Huang, W., and Wang, W. (2016). Inhibiting Shale Hydration and Dispersion with Amine-Terminated Polyamidoamine Dendrimers. J. Nat. Gas Sci. Eng. 28, 52-60. doi:10.1016/j.jngse.2015.11.029

Zou, C., Zhu, R., Chen, Z.-Q., Ogg, J. G., Wu, S., Dong, D., et al. (2019). Organicmatter-rich Shales of China. Earth-Science Rev. 189, 51-78. doi:10.1016/ j.earscirev.2018.12.002

Conflict of Interest: Authors YZ and GY were employed by Sinopec.

The remaining authors declare that the research was conducted in the absence of any commercial or financial relationships that could be construed as a potential conflict of interest.

Publisher's Note: All claims expressed in this article are solely those of the authors and do not necessarily represent those of their affiliated organizations, or those of the publisher, the editors, and the reviewers. Any product that may be evaluated in this article, or claim that may be made by its manufacturer, is not guaranteed or endorsed by the publisher.

Copyright (c) 2021 Wang, Bi, Zeng, Yang, Guo and Yang. This is an open-access article distributed under the terms of the Creative Commons Attribution License (CC $B Y)$. The use, distribution or reproduction in other forums is permitted, provided the original author(s) and the copyright owner(s) are credited and that the original publication in this journal is cited, in accordance with accepted academic practice. No use, distribution or reproduction is permitted which does not comply with these terms. 